\title{
O valor de Saussure para os estudos do discurso*
}

Carlos Piovezani ${ }^{a}$

Allice Toledo Lima da Silveira ${ }^{b}$

\footnotetext{
*Este texto retoma e desenvolve algumas ideias contidas no capítulo "Discursos sobre Saussure: presenças do $C L G$ na Análise do discurso", publicado no livro Saussure: a invenção da Linguística, organizado por José Luiz Fiorin, Valdir Flores e Leci Barbisan e editado pela Contexto, no ano de 2013. As reflexões nele contidas são ainda resultantes de aspectos teóricos desenvolvidos no projeto "Discursos sobre a voz na mídia brasileira contemporânea", que foi financiado pela Fundação de Amparo à Pesquisa do Estado de São Paulo (Processo FAPESP 2014 / 09947 - 3).
}

\begin{abstract}
Resumo
Qual o lugar de Saussure na constituição e no desenvolvimento dos estudos do discurso? Com vistas a refletir sobre o que foi dito a seu respeito por alguns de seus contemporâneos e por outros pensadores nas primeiras décadas e no começo da segunda metade do século XX na Europa, não buscaremos responder a essa questão sem antes expor algumas de suas contingências e examinar certas respostas que a ela poderiam ser dadas. Neste sentido, consideraremos as diferentes recepções do Curso de Linguística Geral na França, que vão desde o momento inicial de sua publicação atéo final da década de 1990. Em seguida, retomaremos a leitura que a Análise do discurso fez da obra de Saussure no final da década de 1960 e no começo da de 1970. Tendo isso em vista, poderemos realizar apontamentos acerca da importância do CLG para Pêcheux e seu grupo, seja como uma obra que se apresenta como um ponto de partida, seja como uma obra a ser recusada.
\end{abstract}

Palavras-chave: Saussure. Valor. Discurso.

a Professor do Departamento de Letras e do Programa de Pós-Graduação em Linguística da Universidade Federal de São Carlos (UFSCar); E-mail: cpiovezani@uol.com.br.

${ }^{\text {b }}$ Doutoranda no programa de Pós-Graduação em Linguística na UFSCar; E-mail: allicesilveira@gmail.com. 


\section{Introdução}

Aos 22 de fevereiro de 1963, em Genebra, Émile Benveniste profere uma conferência que instantaneamente conquistará significativa e considerável repercussão. Trata-se de uma sua homenagem ao cinquentenário do falecimento de Ferdinand de Saussure. Naquela ocasião, Benveniste reiterava a condição de "criador" do homenageado, ou seja, o caráter precursor de seu pensamento, já expresso em seu Mémoire sur le système primitif des voyelles dans les langues indo-européennes, uma vez que ali as vogais não teriam sido consideradas como substâncias fônicas, mas como, mais tarde diria Saussure, entidades distintivas e opositivas; falava da incompreensão de que o suíço foi vítima em sua época, pois ele "estava afastado de seu tempo" e "permanecia sozinho com seus problemas"; relembrava o postulado saussuriano, segundo o qual "a linguagem é sempre um objeto duplo", constituído de dualidades "articulatória e acústica", "do som e do sentido", "do indivíduo e da sociedade", "da língua e da fala", "do material e do não-substancial", "do 'memorial' (paradigmático) e do sintagmático", "da identidade e da oposição", "do sincrônico e do diacrônico"; e insistia na afirmação de seu valor, ressaltando "sua verdadeira grandeza": "Não há um só linguista hoje que não lhe deva algo" (BENVENISTE, 1995, p. 34).

Tanto o caráter distintivo e opositivo das unidades linguísticas quanto a dupla dimensão dos fenômenos da língua relacionam-se com a noção saussuriana de valor, que, por seu turno, articula-se com a natureza arbitrária do signo linguístico, com a ideia de que "a língua é uma forma e não uma substância" e que consiste num "fato social". A noção de valor em Saussure e os postulados que lhe são correlatos são hoje reconhecidos como um dos pontos nucleares da singularidade de seu pensamento. $\mathrm{O}$ que Sechehaye afirmava de modo excepcional ainda no começo do século XX tornar-se-ia praticamente um consenso cinco décadas mais tarde, tal como observamos em "Saussure após meio século", coincidindo justamente com o advento de um campo de saber no contexto francês dos anos de 1960/1970, qual seja, a Análise do discurso (AD).

Com efeito, desde o final do século XIX, falava-se muito do que Saussure dizia sobre o sistema das vogais no indo-europeu, sobre o uso do genitivo em sânscrito e sobre as mudanças 
linguísticas, em geral. Contudo, o genebrino foi alçado à condição de um dos mais célebres pensadores modernos que falaram da língua e da fala humanas graças, principalmente, à publicação de seu ilustre Curso de Linguística Geral (CLG), ou seja, o texto que Saussure parece ter preferido não escrever foi o que postumamente mais repercutiu do conjunto de seus pensamentos, tornando-se sinônimo de seu próprio nome ${ }^{1}$.

Sabemos que já se falou muito e que continuamos ainda a falar bastante do que Saussure falou sobre a língua e a fala. $O$ que foi dito, contudo, desde a publicação do CLG, sobre o que ali teria sido dito por Saussure variou consideravelmente ao longo do tempo e em diferentes espaços. Nosso objetivo aqui é o de expor brevemente parte do que foi dito a seu respeito por alguns de seus contemporâneos e por outros pensadores nas primeiras décadas e no começo da segunda metade do século XX na Europa, no intuito de mais bem interpretar o valor que lhe atribui a Análise do Discurso francesa em determinados textos e contextos ${ }^{2}$. Como a AD leu a obra de Saussure, no final da década de 1960 e no começo da de 1970? O CLG é então para Pêcheux e seu grupo um ponto de partida ou uma obra a ser recusada? Segundo sua perspectiva, qual é o valor a ser dado à noção de "valor" de Saussure e qual sua pertinência para a AD? Nossa reflexão pretende formular algumas possíveis respostas para essas questões, com vistas a analisar os valores atribuídos a Saussure nos estudos do discurso.

1 "Curso de Linguística Geral: um texto chamado 'Saussure"' (NORMAND, 2009, p. 15).

2 É nessa direção que se inscrevem os trabalhos de Puech (2005), Cruz (2006 e 2011) e Piovezani (2008 e 2009, neste último, particularmente, a passagem entre as páginas 159-163). Os argumentos contidos nesses textos serão aqui reiterados e, por vezes, desenvolvidos, de acordo com nossas limitações de fôlego e espaço.

\section{Percursos do Curso: recepções do pensamento de Saussure}

A partir de sua publicação, o CLG suscitou variados tipos de interesse, adesão, críticas e recusas (não necessariamente nessa ordem). Em distintos contextos, diferentes sujeitos produziram diversos discursos sobre Saussure. Hoje, conhecemos relativamente bem o percurso de seu pensamento: algumas de suas ideias mais ou menos consoantes com o método histórico-comparativo começaram a circular em Genebra, Leipzig e Paris, a partir do final do século XIX; outras, inscritas no campo convencionalmente chamado de Linguística geral, ganharam o mundo no início do século seguinte, com sua difusão pelo Leste Europeu, principalmente, em Moscou e em Praga, passando, em seguida, por Copenhague e Nova Iorque, 
até sua volta efervescente e triunfante, porque concebidas como signo de modernidade científica, a Paris, nos pós-guerras. Seguindo contígua e simplificadamente a arguta proposta de Puech (2005, p. 96-97) acerca das recepções do CLG na França, traçamos abaixo um esquema de seu trajeto:

- Sua primeira recepção ocorreu já no momento imediatamente seguinte ao da publicação do Curso e nela prevaleceram, ao lado de um relativo desinteresse de parte dos linguistas, uma avaliação negativa, tendo em vista o que diziam ser sua natureza demasiadamente especulativa e abstrata, em comparação com o rigor do Mémoire sur le système des voyelles en indo-européen. Meillet e Vendryès, entre outros, reprovaram Saussure pela desconsideração de aspectos sociais empíricos e, por extensão, da covariação entre língua e sociedade.

- Já a segunda recepção do pensamento de Saussure desenvolveu-se, durante o período entre as duas Grandes Guerras, somente junto a alguns poucos e isolados linguistas franceses, sem ainda provocar maiores repercussões. Por outro lado, em parte do Leste Europeu, desde o final dos anos 20, o CLG era concebido como um fundamental ponto de partida, na medida em que trazia consigo uma reflexão linguística inovadora.

- Após a Segunda Guerra Mundial, acontece então a terceira recepção. Saussure agora extrapola o domínio relativamente restrito dos círculos linguísticos e o CLG torna-se, na França, principalmente a partir da década de 1950, uma leitura fundamental também para antropólogos, sociólogos, críticos literários, filósofos e psicanalistas. Sua circulação nesse contexto francês é frequentemente intermediada, principalmente, pelas interpretações de Jakobson e de Hjelmslev.

- A quarta recepção surge com a descoberta e publicação das fontes manuscritas, desde o fim dos anos de 1950. Baseando-se nos manuscritos e nas edições críticas do CLG, inicia-se no final da década de 1990, na França, um conjunto de trabalhos filológicos, cujos fins consistem essencialmente no retorno a Saussure, visando a revelar 
o seu suposto verdadeiro pensamento, que teria sido subvertido por Bally e Sechehaye na edição do Curso.

A simplicidade do quadro que escande certos rumos trilhados pelo CLG revela, em contrapartida, a considerável complexidade da circulação da obra de Saussure. Por seu intermédio, sempre na esteira de Puech (2005), podemos concluir i) que suas ideias foram consideradas marginais durante aproximadamente quatro décadas na França, ii) que elas apenas tardiamente suscitaram ali um amplo interesse da geração "estruturalista" e iii) que sua interpretação nesse contexto francês foi sensivelmente condicionada por leituras intermediárias. Talvez a ponderação sobre a existência dessas grades e prismas de recepção que se interpõem entre o Curso e seus leitores de diferentes épocas e lugares possa contribuir para enfraquecer as repetições eivadas de teleologia, conforme as quais Saussure é fácil e exclusivamente representado como origem (e fim) da Linguística moderna. Alhures, Puech já afirmara oralmente que as recepções do Curso demonstram de maneira emblemática um dos mais importantes princípios semiológicos ali mesmo postulados: "o tempo altera todas as coisas; não existe razão para que a língua escape a essa lei universal" (SAUSSURE, 2000, p. 91).

Uma vez que se trata de matéria histórica, o CLG foi objeto, em conjunturas singulares, de diferentes interpretações, materializadas em discursos que, eventualmente e em última instância, até se opõem. Ele foi para alguns uma perversão do Saussure "real", o comparatista, não consistindo, portanto, numa obra nem fundamental nem tampouco fundadora. Ao então identificar a novidade contida no Curso, sustentando que "a ciência da língua será uma ciência dos valores", Sechehaye era, antes, entre seus pares, uma exceção, que confirmava ser outra a regra quanto à compreensão do pensamento saussuriano. Por volta de quinze anos mais tarde, em dois pontos distintos da URSS, Saussure era interpretado de modo sensivelmente diverso e ambivalente: enquanto os membros do Círculo Linguístico de Moscou (entre os quais se encontravam Jakobson e Tynianov) acolhiam-no favoravelmente, atribuíamlhe um caráter inovador e apontavam-lhe uma ou outra inconsistência, os componentes do Grupo de São Petersburgo (Bakhtin e Volochinov, entre outros), reconheciam-lhe algum 
mérito, mas, predominantemente, refutavam-no, alegando seu descaso para com a dimensão social das interações linguísticas (AGEEVA, 2009).

Se Saussure não esteve ausente do pensamento linguístico da Europa Ocidental desde 1916 e do Leste Europeu no final da década de 1920, ele conhecerá certa ubiquidade na França, somente a partir da segunda metade do século XX. No interior do "estruturalismo francês", o CLG será uma referência obrigatória ou ao menos uma forte inspiração para os linguistas, mas também para Lévi-Strauss, Greimas, Althusser, Lacan, Barthes, Foucault e Derrida. Contudo, segundo Puech (2011), muitas menções ao paradigma estruturalista francês não consideram suficientemente sua heterogeneidade interna, seu retardo no acolhimento das ideias de Saussure, sua duração efêmera e sua autoconcepção como pura ruptura com os "humanismos" do período anterior. Com efeito, a suposta prosperidade do pensamento saussuriano na França caracterizar-se-ia pela ausência de uma sua efetiva "recepção" nas primeiras décadas do século XX e pela presença de uma sua relativa "herança" nos anos de 1950-60, durante os quais Saussure teria desempenhado o papel de uma "origem adormecida", cujo despertar possibilitaria uma forma absolutamente nova de conceber a língua, o texto, a narrativa, as relações de parentesco, o inconsciente, a moda, o sujeito e tudo mais que fosse constituído de linguagem.

Enquanto, na primeira metade do século XX, Jakobson e Hjelmslev consideravam o Curso como uma obra fundadora e fundamental, mas não cabalmente desenvolvida - consideração que exigia seu desdobramento, ampliação e aperfeiçoamento -, no estruturalismo francês prevaleceu a concepção de que o CLG era um texto fundador, fundamental e acabado, do qual se deveria partir e, ao mesmo tempo, em relação ao qual era preciso se opor, para tratar de outros fenômenos e domínios ${ }^{3}$. Um aspecto da ambivalência contida nessa interpretação parece intensificar-se no advento de várias teorias linguísticas contemporâneas. Seus proponentes costumam atribuir a Saussure a instauração da Linguística moderna, reivindicam

${ }^{3}$ Cf. Chiss e Puech (1999; particularmente o item 4. "La fabrication du discours disciplinaire", p. 33-41) e Cruz (2006, p. 175). eventualmente seu legado e situam-se mais ou menos na ascendência de seu pensamento, mas advogam também o dever e a capacidade de ultrapassá-lo. Por um lado, conferem a Saussure o mérito de ter estabelecido a autonomia de um objeto 
e a positividade científica de uma teoria e de um método; por outro, reclamam a necessidade de eleger como objeto de estudo aquilo que teria sido excluído de suas considerações, ou seja, a fala e a variação linguística, o sujeito, a história e o sentido.

Sabemos que, entre as décadas de 1950 e 1970, surgiram e/ou fortaleceram-se várias tendências no interior da ou em diálogo com a Linguística: a Sociolinguística, a Teoria da enunciação, a Pragmática, a Linguística textual, a Semiótica, a Análise da conversação e a Análise do discurso. Talvez mais os arautos e divulgadores desses campos que propriamente seus precursores, cada um a seu modo, ao contar a própria história de seu surgimento ou ao anunciar a necessidade de sua emergência, tendem direta ou indiretamente a reconhecer algumas das contribuições, mas também a afirmar as falhas e lacunas de seus antecessores: Hymes, por exemplo, critica a noção de "competência linguística", de Chomsky, e propõe sua substituição pela de "competência comunicativa". Contudo, frequentemente parece ter sido Saussure, mais que Chomsky, o herói reconhecido, mas também o maior vilão e a principal vítima dos ataques que lhe foram infligidos por linguistas da fala, do texto, da enunciação e do discurso. Ora, aqui podemos vislumbrar as duas faces pespegadas em Saussure: a do "pai fundador", que amorosamente possibilitou a concepção da disciplina, e a do "pai censor", que odiosamente interditou seu pleno desenvolvimento.

Não parece haver exatamente um equilíbrio entre a fundação e a censura nessas interpretações sobre Saussure. Para contemplar o domínio da enunciação, Jakobson crê ser preciso alterar a distinção entre língua e fala, separando a dimensão semiótica da comunicativa, no intuito de integrar esta última aos estudos linguísticos; já Benveniste postula, para tanto, a necessidade de continuar e completar a proposta saussuriana. Embora ambos falem em "integrar" a enunciação, suas propostas são sensivelmente diferentes: no primeiro, há a ideia de uma transcendência, de uma exterioridade da comunicação em relação à língua, no segundo, prevalece a concepção de uma ligação imanente e constitutiva entre a língua e seu uso ${ }^{4}$. De modo geral, as teorias sociolinguísticas, textuais e pragmáticas tendem a enfatizar o que acreditam ser as exclusões e interdições produzidas por Saussure, a despeito do reconhecimento de suas conquistas científicas, ao passo 
que Semiótica francesa, derivada de Greimas, parece realçar a fundação e a filiação ao seu pensamento, ainda que o tenha enriquecido com importantes ampliações ${ }^{5}$.

São esses alguns dos dizeres sobre o que disse ou teria dito Saussure. Em seguida, tentaremos identificar certos traços do que foi dito pela $\mathrm{AD}$ francesa a seu respeito, no intuito de aventar algumas respostas às questões formuladas acima e às suas seguintes extensões: ao falar de Saussure, a AD empreendeu uma recepção do CLG e/ou constituiuse como uma sua herança? Enfatizou a continuidade ou a descontinuidade entre o pensamento saussuriano e a emergência do discurso como seu objeto de análise? Que posição assumiu essa voz discursiva, que também ela ecoou à sua maneira a fala de Saussure? Enfim, qual o valor que a AD atribuiu e atribui ao "valor" de Saussure?

\section{O valor do CLG para a Análise do discurso na França}

Já na introdução de Análise automática do discurso (AAD 69), concebido tanto como "conclusão das reflexões epistemológicas desenvolvidas desde aproximadamente 1966" quanto como "ponto de partida da 'aventura teórica do discurso'" (MALDIDIER, 2011, p. 42), Michel Pêcheux fala do "deslocamento conceptual introduzido por Saussure", ao separar a teoria da linguagem do uso da língua: "a partir do momento em que a língua deve ser pensada como um sistema, deixa de ser compreendida como tendo a função de exprimir sentido; ela torna-se um objeto do qual uma ciência pode descrever o funcionamento" (PÊCHEUX, 1997a, p. 62). Com Saussure, a linguística teria deixado de ser uma "ciência da expressão e de seus meios", cujo fim era a compreensão de um texto, para tornar-se uma ciência da língua, cujo objetivo passou a ser a descrição das regras de combinação e substituição de suas unidades. Em seguida, Pêcheux observa que, conforme sempre acontece na história da ciência, a constituição da cientificidade de um campo de saber mediante a delimitação de seu objeto implica deixar a descoberto o terreno que ela abandona. Por não haver aí nada de disfórico, seria “absurdo censurar a linguística por se restringir a seu objeto: 
campo aquilo que, até então, o perseguia, no exato sentido do termo" (PÊCHEUX, 1997a, p. 69).

Eis aqui, no entanto, o retorno do que fora recalcado, uma vez que questões como "O que quer dizer este texto? Que significação contém este texto? Em que o sentido deste texto difere daquele de tal outro texto" continuam a frequentar a linguística e outras ciências sociais. Segundo Pêcheux: "a linguística excluiu de seu campo as questões do sentido, da expressão das significações contidas nos textos"; tal fato fez com que essas questões fossem respondidas a seu modo por várias ciências sociais e insistissem ante a linguística para serem resolvidas (PÊCHEUX, 1997a, p. 63; PÊCHEUX, 2011, p. 69).

As tentativas deresponder a essas perguntas empreendidas por diversas áreas das ciências humanas serão duramente criticadas por Pêcheux. A despeito de suas críticas incidirem também sobre "os métodos não-linguísticos", executados pela lexicometria e pela análise de conteúdo, seu principal alvo são "os métodos para-linguísticos, ainda chamados de "estudo das 'linguagens"' e "aplicação metafórica da linguística". Na perspectiva de Pêcheux, o equívoco fundamental dessas abordagens paralinguísticas, entre as quais se encontram, por exemplo, a antropologia de Lévi-Strauss, a semiologia de Barthes, a semiótica de Greimas e a semântica de Pottier, reside na "homogeneidade epistemológica que se supõe entre os fatos da língua e os fenômenos da dimensão do texto" (PÊCHEUX, 1997a, p. 66-67).

Considerando particularmente a oposição entre língua e fala e o conceito de instituição, Pêcheux passa a tratar, na sequência, de passagens do CLG. De acordo com o filósofo francês, Saussure teria estabelecido "duas exclusões teóricas": a fala e as instituições políticas e jurídicas. Frequentemente censurava-se Saussure pela suposta exclusão da fala; a Análise do discurso proposta por Pêcheux, por sua vez, condenava, antes, uma das consequências da dicotomia "língua/fala", qual seja, o par "sistema x liberdade". Assim, decorreria da oposição saussuriana "a reaparição triunfal do sujeito falante como subjetividade em ato, unidade ativa de intenções que se realizam pelos meios colocados a sua disposição" (PÊCHEUX, 1997a, p. 71). O conceito filosófico de sujeito falante livre seria o correlato necessário do sistema linguístico. A crítica frontal à condição da fala como "caminho da liberdade humana" é acompanhada 
${ }^{6}$ Ao qual o autor não faz referência explícita em $A A D$ 69; diferentemente do que ocorria à época, quando Pêcheux publicou dois textos sob o pseudônimo de Thomas Herbert, nos quais Marx e Althusser são presenças manifestas $\mathrm{e}$ fundamentais. Tratavase, segundo Henry (1997, p. 14) de "uma estratégia $\mathrm{cu}$ id a d os a mente deliberada", cujo objetivo era o de "abrir uma fissura teórica e científica no campo das ciências sociais". por outra, mais discreta, à autonomia absoluta da língua em relação à sua "exterioridade". Contudo, a consideração dos dois polos da distinção saussuriana - de um lado, o caráter universal da língua e, de outro, a dimensão individual da fala - é um dos fatores que permitem a Pêcheux conceber, com base no materialismo histórico ${ }^{6}$, o âmbito particular do discurso. Talvez pudéssemos vislumbrar aqui o delineamento da ideia, cara à $\mathrm{AD}$, da língua como base relativamente autônoma a partir da qual são produzidos os diversos processos discursivos.

Uma vez que a análise dos processos discursivos supõe o estudo das relações de força e de sentido presentes em determinadas condições de produção do dizer, o projeto de Pêcheux não aceita o que ele então chama de oposição saussuriana entre os sistemas institucionais jurídicos e políticos e os sistemas institucionais semiológicos. Aos olhos de Pêcheux, tal oposição faria com que o pronunciamento de um deputado na Câmara fosse concebido do ponto de vista de Saussure como algo da ordem da fala, como a expressão da liberdade do locutor, ao passo que um sociólogo o tomaria como parte de um mecanismo institucional, cujo funcionamento compreende "um sistema de normas nem puramente individuais nem globalmente universais, mas que derivam da estrutura de uma ideologia política, correspondendo, pois, a um certo lugar no interior de uma formação social dada" (PÊCHEUX, 1997a, p. 76-77). O funcionamento do dizer não é integralmente linguístico e, por essa razão, somente pode ser analisado por meio da consideração dos protagonistas e do objeto do discurso inscritos em certas condições de produção e de sua relação com outros dizeres. Em função da importância que lhe é atribuída, Pêcheux discorrerá detalhadamente sobre as condições de produção, no interior das quais o discurso determina o dizer e produz "efeito de sentidos" entre os interlocutores.

A referência a Saussure retorna no momento em que, ao refletir sobre a produção dos sentidos, Pêcheux critica a "concepção atomística das significações", na qual, em detrimento das relações entre as formas, prevalecem as "unidades decomponíveis em 'semas' que existem por si", e volta a referir-se a Saussure. A teoria do valor está no horizonte, quando se dá a elaboração da noção de "efeito metafórico", que consiste na abordagem discursiva do "fenômeno semântico produzido por uma substituição contextual" (PÊCHEUX, 1997a, 
p. 93-96). Na esteira do distribucionalismo de Zellig Harris e do que mais tarde (HAROCHE, HENRY, PÊCHEUX, 1971, p. 96) seria chamado de "princípio da subordinação da significação ao valor", Pêcheux desenvolve a ideia segundo a qual os sentidos não são essenciais às unidades $x$ e $y$, mas derivam da relação que eles estabelecem entre si e do deslizamento de um termo a outro. Tratava-se de uma concepção não-essencialista do sentido possibilitada por Saussure, cujo desdobramento encontra-se formulado do seguinte modo: "o ponto essencial aqui é que não se trata somente da natureza das palavras empregadas, mas também e, sobretudo, das construções nas quais essas palavras se combinam, na medida em que essas construções determinam a significação que essas palavras terão", isto é, "as palavras mudam de sentido segundo as posições daqueles que as empregam. (...) as palavras 'mudam de sentido' ao passar de uma formação discursiva para outra" (PÊCHEUX, 2011, p. 73).

$\mathrm{O}$ argumento de que tanto a linguística estrutural quanto outras ciências humanas que dela se apropriaram procediam equivocadamente ao tentar abordar a dimensão semântica do uso da língua é o ponto de partida para o desenvolvimento da ideia central do texto "Língua, linguagens, discurso". Analisar apropriadamente a produção dos sentidos impõe uma "mudança de terreno", isto é, exige a adoção de uma perspectiva materialista que a concebe como efeito das "relações sociais, que resultam de relações de classe características de uma dada formação social" (PÊCHEUX, 2011, p. 72). Essa tese encontra-se desenvolvida em "A semântica e o corte saussuriano: língua, linguagem, discurso" (HAROCHE, HENRY, PÊCHEUX, 1971), em cujo decurso a presença de Saussure é quase uma obsessão que já se prenuncia no próprio título: seu nome é repetido vinte e uma vezes, o CLG, mencionado em oito ocasiões; mesmo número de reproduções do adjetivo "saussuriano(a)". Após afirmar que um dos aspectos mais originais do projeto de Pêcheux residia em sua vontade de articular a ordem da língua à do discurso, Puech aventa a hipótese de que um dos motes de "A semântica e o corte saussuriano" é a seguinte questão: "qual é o lugar do saussurismo na emergência de uma categoria de 'discurso' elaborada no próprio terreno da linguística?" (PUECH, 2005, p. 108).

Em "A semântica e o corte saussuriano" há ao menos três posições em relação ao pensamento de Saussure. Podemos 
observar, por um lado, um reconhecimento de suas conquistas científicas: ele empreendeu um corte epistemológico e fundou a linguística como ciência, afastando-se das evidências empíricas e concebeu o "princípio da subordinação da significação ao valor", cujos efeitos foram a possibilidade de constituição da fonologia, da morfologia e da sintaxe e o "corte pela raiz de qualquer retorno do sujeito, quando se trata de língua" (HAROCHE, HENRY, PÊCHEUX, 1971, p. 96). É possível também entrevermos uma defesa dessa ruptura, uma referência à relativa desatenção quanto a um de seus aspectos e um ataque àqueles que "em seu nome, procederam, em certa medida, de modo inverso" (HAROCHE, HENRY, PÊCHEUX, 1971, p. 94 e 99). Constatamos, por outro lado, a reiteração da crítica endereçada a Saussure por sua adesão à "ideologia individualista e subjetivista da 'criação'" (HAROCHE, HENRY, PÊCHEUX, 1971, p. 98) presente tanto em sua concepção do fenômeno linguístico da analogia, que se inscreveria no âmbito da fala e do sujeito individual (HAROCHE, HENRY, PÊCHEUX, 1971, p. 95), quanto na oposição entre a língua e a fala, que recobriria "a dupla ideológica liberdade/coerção, criatividade/ sistema" (HAROCHE, HENRY, PÊCHEUX, 1971, p. 98).

A onipresença ambivalente de Saussure e a reflexão sobre os desenvolvimentos da linguística serão passagens obrigatórias para mostrar a possibilidade e a necessidade de uma "mudança de terreno" na abordagem da produção dos sentidos na sociedade. Quatro anos mais tarde, em seu grande livro, Les vérités de la Palice (trad. bras. "Semântica e discurso", 1997b), Pêcheux desenvolverá a ideia de que é justamente a semântica o ponto nevrálgico da linguística, que oscila entre as tendências "formalista-logicista", "históricosociológica" e "linguística da fala" (entre as quais se estabelecem laços contraditórios e constroem-se formas intermediárias), ao defrontar-se com o engendramento das significações, sem jamais aí considerar devidamente o caráter necessário e constitutivo das relações sociais. É o conceito de discurso que permite fazê-lo. Sua concepção e análise requerem uma teoria do discurso forjada na intervenção do materialismo histórico na linguística. Articulando a "ciência das formações sociais" à "ciência linguística", Pêcheux consolida a oposição entre "base linguística" e "processos discursivos", distingue o "interdiscurso" do "intradiscurso" e demonstra 
7 Por essa razão, Puech sustenta que "no contexto francês, a emergência de uma 'ordem do discurso' apenas pôde se manifestar numa proximidade polêmica com o paradigma estruturalista então unanimemente referido - ainda que em graus diversos - a Ferdinand de Saussure." (2005, p. 94).

8 "Quer seja, portanto, em uma filosofia do sujeito fundante, quer em uma filosofia da experiência originária ou em uma filosofia da mediação universal, o discurso nada mais é que umjogo de escritura, no primeiro caso, de leitura, no segundo, de troca, no terceiro, e essa troca, essa leitura e essa escritura jamais põem em jogo senão os signos. O discurso se anula, assim, em sua realidade, inscrevendo-se na ordem do significante." (FOUCAULT, 2000, p. 49) a interdependência existente entre eles no funcionamento do "pré-construído" e do "discurso-transverso" (PÊCHEUX, 1997b, p. 90-91; 162-168).

A despeito de todas essas propostas e desenvolvimentos do discurso que concernem à linguística, à semântica e à filosofia, conforme o subtítulo original de sua obra, as referências explícitas a Saussure são bem menos frequentes e resumem-se a retomadas de ideias formuladas a seu respeito em textos anteriores. Depois de uma alusão tangencial ao CLG e a seu "autor", por meio da qual Pêcheux visava a diferenciar "uma série de estudos semiológicos, incidindo sobre os sistemas da moda, da publicidade, dos sinais de trânsito, relações de parentesco, mito, etc.", que "dizem respeito ao conjunto de signos", da "Semântica, cuja definição mais geral é a de que ela se ocupa do sentido" (PÊCHEUX, 1997b, p. 12), Saussure voltará a ser manifestamente mencionado apenas quarenta e oito páginas adiante. Ali, são reiteradas as ideias do "corte epistemológico" empreendido pelo mestre genebrino mediante a inversão da "relação entre significação e valor" e de sua adesão à ideologia subjetivista materializada em sua maneira de conceber a "criação analógica" e na "oposição da subjetividade criadora da fala à objetividade sistemática da língua" (PÊCHEUX, 1997b, p. 60).

O lugar de Saussure no advento da "ordem do discurso" é ao mesmo tempo central e controverso ${ }^{7}$. Enquanto Foucault concebe a "ordem da língua" como um obstáculo à constituição do discurso como objeto de conhecimento ${ }^{8}$ - para "restituir ao discurso seu caráter de acontecimento" era preciso "suspender, enfim, a soberania do significante" (FOUCAULT, 2000, p. 51) -, Pêcheux a considera como um ponto do qual se deve partir e o qual se deve ultrapassar. A língua é base para os processos discursivos, é possibilidade para o discurso e lugar privilegiado para sua materialização. Porém, o funcionamento da discursividade não é integralmente linguístico, visto que a "relação que liga as 'significações' de um texto às condições sócio-históricas desse texto não é de modo algum secundária, mas constitutiva das próprias significações." (HAROCHE, HENRY, PECHEUX, 1971, p. 98). Foucault afirmava que Saussure era "o fundador da linguística" (1992, p. 60), mas parece não ter nele reconhecido o portador de um pensamento fundamental. Na perspectiva de Pêcheux, o CLG configura-se 
como uma obra fundadora e fundamental, mas igualmente perpassada pelo recobrimento ideológico que põe em xeque a própria ruptura que ela aporta. Considerando essa ambivalência, Puech (2005, p. 109) dirá que, em Pêcheux, a emergência da "ordem do discurso" somente poderia ocorrer com e contra Saussure.

Saussure será evocado de modo análogo por outros analistas do discurso na década de 1970 na França. É o caso, por exemplo, de Régine Robin (1977), em "História e linguística". No item "Língua e discurso" de seu primeiro capítulo, antes de apresentar a definição do segundo termo, tal como se fosse uma condição necessária para fazê-lo, a autora refere-se a Saussure nos seguintes termos: "A Linguística constituiuse, enquanto ciência, a partir de Saussure - tudo isto é bem conhecido" (ROBIN, 1977, p. 24). A ruptura produzida pelo CLG era então concebida como uma evidência. Na sequência, Robin discorre sobre a distinção entre língua e fala, reiterando as seguintes ideias: essa oposição representa o recobrimento do sistema pelo acidental, da instituição social pelo individual, pela "subjetividade do locutor"; e a linguística derivada de Saussure permite a descrição dos níveis linguísticos inferiores à semântica. Quando a linguística tenta abordar os sentidos, "oscila entre o domínio da língua e o da fala", produzindo "muitas confusões e mal-entendidos". Segundo Robin, o historiador "não tem que lidar com o código, com a língua", devendo tomá-los como "base"; "seu objeto (...) não é o sistema, o modelo de competência, a língua, mas fatos de fala precisos, ficando entendido que convém desembaraçar o termo de suas conotações filosóficas precedentemente evocadas - numa palavra, dos discursos". (ROBIN, 1977, p. 25).

Vinte anos mais tarde, as palavras de Denise Maldidier ecoam a afirmação de Robin: "Michel Pêcheux constitui o discurso como uma reformulação da fala saussuriana, desembaraçada de suas implicações subjetivistas" (MALDIDIER, 2003, p. 22); "o discurso reformula a fala, esse 'resíduo filosófico', cujas implicações subjetivistas devem ser eliminadas." (2011, p. 44). Nesse intervalo, entretanto, as interpretações do papel desempenhado por Saussure na emergência da Análise do discurso não passarão incólumes pela "quarta recepção" do CLG na França. É por essa razão que diferentemente do que ocorria outrora, quando a tendência entre os analistas do discurso era 
${ }^{9}$ Há ainda outros textos em que a referência a Saussure é importante para Pêcheux, tal como ocorre, em La langue introuvable, escrito com Gadet e publicado em 1981. Uma análise do modo como Saussure é ali interpretado pode ser encontrada em Cruz (2006, p. 173-4). a de enfatizar as descontinuidades de Pêcheux em relação a Saussure, em função do suplemento que o primeiro aportava nas faltas do segundo, Maldidier insiste na importância de Saussure para o precursor da AD: “O conceito de discurso é forjado a partir de uma reflexão crítica sobre o corte fundador operado por Saussure e não sobre sua superação"; Pêcheux é "resolutamente saussuriano desde o princípio" (MALDIDIER, 2011, p. 44 e 49); "As páginas que Michel Pêcheux consagra a Saussure guardaram sua força”; "O discurso construído por Michel Pêcheux não invoca de forma alguma a "superação" da dicotomia língua/fala. Saussure é, para ele, o ponto de origem da ciência linguística." (MALDIDIER, 2003, p. 21-22).

Na própria obra de Pêcheux há certa variação nas presenças e ausências de Saussure e nos julgamentos feitos a seu respeito e no valor que lhe é atribuído. Em AAD 69, A semântica e o corte saussuriano e Semântica e discurso, ele está presente e, na ambivalência do modo como é avaliado, fundador e censor, parece predominar a necessidade de "mudança de terreno" e de superação de seus limites. Em contrapartida, motivo para um nosso estranhamento, não encontramos referência explícita ao nome de Saussure no artigo escrito com Fuchs e publicado em 1975, nem no texto "Há uma via para a linguística fora do logicismo e do sociologismo?", escrito com Gadet e publicado em 1977, e no artigo "Sobre os contextos epistemológicos da Análise de discurso", publicado postumamente em 1984. Em Discurso: estrutura ou acontecimento, conferência proferida em 1983, há duas menções ao nome de Saussure, a quem, em conjunto com Marx e Freud, atribui-se a produção de um "efeito subversivo (...) que coloca em causa as evidências da ordem humana como estritamente biossocial" (PÊCHEUX, 1997c, p. 45). Por fim, em "Sobre a (des)construção das teorias linguísticas", texto publicado em 1982, Saussure é onipresente e seu pensamento, concebido como um "ponto inaugural que permanece evanescente", como uma ruptura que as teorias linguísticas posteriores jamais levaram a cabo e em relação à qual sempre oscilaram entre "diásporas reais" e "reunificações enganadoras" (PÊCHEUX, 1998, p. 9) 9 . 


\section{Por que falamos tanto... e de Saussure?}

Ressurgindo no decurso do tempo, em diferentes lugares, sob a forma de distintas condições, a fala de Saussure sobre a língua e fala humanas foi constantemente retomada. Seu dizer sobre nossa linguagem estabeleceu "uma possibilidade indefinida de discursos", tal como afirma Foucault (1992) a propósito dos "fundadores de discursividade". Ali mesmo, porém, o filósofo francês atribuíra a Saussure a qualidade de "fundador de cientificidade". Ao passo que o dizer deste segundo encontra-se no mesmo plano das transformações que ele torna possíveis e compreende "redescobertas" e "reatualizações" do que fora dito, o do primeiro proporciona um "retorno a", que produz outros dizeres ante os quais se constitui como falta e excesso, porque se presume haver na discursividade fundadora ao mesmo tempo um vazio e uma plenitude. Após traçar as diferenças entre a "instauração discursiva" e a "fundação científica", Foucault acrescenta que elas não são necessariamente incompatíveis.

Embora talvez já fosse possível também conceber Saussure no contexto do estruturalismo francês dos anos de 1960/70 como um "fundador de discursividade", é compreensível que Foucault o tenha tomado como "fundador" da "ciência piloto". Certamente, o CLG produziu "redescobertas" e "reatualizações" da ciência, mas também promoveu dizeres sob a forma de "retornos", porque nele foram e continuam a ser concebidas sobras e lacunas.

Ao comentar noutro contexto o estatuto que atribuía ao marxismo e à psicanálise, Foucault afirmava que ambos consistem em "tipos de discursos e práticas, cuja importância para nossa sociedade e para nossa história independe do estatuto de ciência que possam vir a receber." (1996, p. 35). Tal como Marx e Freud, porque nem gênio de pensamento isolado, que emerge ex nihilo, nem mero peixe dentro do aquário, que nada vê além de seus limitados limites, Saussure continua e rompe com sua tradição, para definitivamente estabelecer um amplo, novo e aberto campo de possibilidades de fala sobre nosso dizer, cujos sentidos são arbitrários e relativos, e para produzir algo mais importante que uma ciência. Assim, a despeito de suas diferenças, há dizeres de Saussure que repercutiram e que continuam a reverberar em vários campos 
do saber, em diferentes épocas e em diversos lugares, inclusive, a seu modo, na Análise do discurso: a ordem da língua, que não se reduz à lógica nem corresponde à natureza do mundo, com sua relativa autonomia em relação à sua exterioridade e com sua opacidade e a condição de valores relacionais de suas formas. Não haveria inegáveis pontos de contato entre a ideia de conceber as formas linguísticas como valores, que "são puramente diferenciais, definidos não positivamente por seu conteúdo, mas negativamente por suas relações com os outros termos do sistema” (SAUSSURE, 2000, p. 136), e a concepção de sentido como sendo resultante do "sistema de relações de substituição, paráfrases, sinonímias, etc., que funcionam entre elementos linguísticos - 'significantes' - em uma formação discursiva dada" (PÊCHEUX, 1997b, p. 161)? Ainda que "história" e "sociedade" não sejam evidentemente concebidas da mesma maneira por Saussure e Pêcheux, de modo análogo ao que ocorre na teoria semiológica saussuriana, que entende as relações sociais como fundamento constitutivo da língua, a AD compreende a historicidade (isto é, as relações de força e de sentido entre os sujeitos de uma sociedade) como dimensão inscrita no âmago dos usos da língua. No discurso, a língua está na história e a história, na língua.

Há tempos, usamos nossa faculdade de linguagem, nossa capacidade idiomática e nossa competência discursiva para ouvir e ler Saussure e para falar e escrever sobre o que ele dissera de nossa língua e de nossa fala. Fazemo-lo ainda e sempre, porque há tempos o Curso de Linguística Geral tornou-se um clássico, texto que não deixamos de reler, porque nos diz de uma só vez o seu tempo e a novidade que introduz ${ }^{10}$. Talvez ainda de distintos modos duas mortes tenham contribuído para que tanto se fale do que disse Saussure sobre a fala humana: a do homem, que eliminou possibilidade de réplica às objeções, mas, sobretudo, a do autor, que deu à escrita o seu devir. Essas mortes não representaram o fim de Saussure; antes, consistiram no começo de uma vida muito longa e produtiva, afirmada antes e depois daqueles 22 de fevereiro de 1963, em que Benveniste, cinquenta anos após o falecimento do mestre suíço, declarava nossas dívidas, gratidão e reconhecimento, que poderiam verter-se num lugar-comum aqui bastante

${ }^{10}$ Cf. Normand (2009, p. 20). apropriado: os clássicos nunca morrem. Saussure jamais morrerá enquanto continuar a nos ensinar que falamos tanto de 
nossa fala para reafirmarmos nossa própria condição humana. Não cremos que cessará de fazê-lo tão cedo. Entre as quatorze definições propostas por Italo Calvino para explicar o que são os "clássicos", talvez uma das mais singelas seja já suficiente para compreender por que razão o CLG goza dessa condição: "Um clássico é um livro que nunca terminou de dizer aquilo que tinha para dizer." Eis o inestimável valor de Saussure não apenas para os estudiosos do discurso, mas para todos aqueles que se interessam por algo mais ou menos trivial e absolutamente excelso como é a fala nossa de cada dia.

\section{REFERÊNCIAS}

AGEEVA, I. La critique de F. de Saussure dans Marxisme et philosophie du langage de de V. N. Vološinov et le contexte de la réception des idées saussuriennes dans les années 19201930 en Russie. Cahiers de l'Institut de Linguistique et Sciences du Langage. Genève, n. 26, p. 73-84, Droz, 2009.

BENVENISTE, E. Problemas de linguística geral. Campinas: Editora da Unicamp/Pontes, 1995.

CHISS, J. L.; PUECH, C. Le langage et ses disciplines (XIXè-XXè siècles). Paris/Bruxelas: De Boeck et Larcier, 1999.

CORTINA, A.; MARCHEZAN, R. F. C. Teoria Semiótica: a questão do sentido. In: BENTES, A. C.; MUSSALIN, F. (Org.). Introdução à linguística: fundamentos epistemológicos. São Paulo: Cortez, 2004. v. 3, p. 393-438.

CRUZ, M. A. O saussurismo e a escola francesa de análise do discurso: ruptura ou continuidade. Tese. UFAL, 2006.

CRUZ, M. Saussure, as teorias linguísticas contemporâneas e a Análise do discurso. In: SARGENTINI, V.; PIOVEZANI, C.; CURCINO, L. (Org.) Discurso, Semiologia e História. São Carlos: Claraluz, 2011, p. 67-80.

FOUCAULT, M. O que é um autor? Lisboa: Vega, 1992.

FOUCAULT, M. et al. O homem e o discurso. Rio de Janeiro: Tempo Brasileiro, 1996. 
FOUCAULT, M. A ordem do discurso. São Paulo: Loyola, 2000.

HAROCHE, C.; HENRY, P.; PÊCHEUX, M. La sémantique et la coupure saussurienne: langue, langage, discours. Langages. Paris, v. 6, n. 24, p. 93-106, 1971.

HENRY, P. Os fundamentos teóricos da "Análise automática do discurso" de Michel Pêcheux (1969). In: GADET, F.; HAK, T. (Org.) Por uma Análise automática do discurso: uma introdução à obra de Michel Pêcheux. Campinas: Editora da Unicamp, 1997, p. 13-38.

MALDIDIER, D. A inquietação do discurso: (re)ler Michel Pêcheux hoje. Campinas: Pontes, 2003.

MALDIDIER, D. A inquietude do discurso. Um trajeto na história da Análise do discurso: o trabalho de Michel Pêcheux. In: PIOVEZANI, C.; SARGENTINI, V. (Org.) Legados de Michel Pêcheux: inéditos em Análise do discurso. São Paulo: Contexto, 2011, p. 39-62.

NORMAND, C. Saussure. São Paulo: Estação Liberdade, 2009.

PÊCHEUX, M. Análise automática do discurso. In: GADET, F.; HAK, T. (Org.) Por uma Análise automática do discurso: uma introdução à obra de Michel Pêcheux. Campinas: Editora da Unicamp, 1997a, p. 61-161.

PÊCHEUX, M. Semântica e discurso: uma crítica à afirmação do óbvio. Campinas: Editora da Unicamp, 1997b.

PÊCHEUX, M. Sobre a desconstrução das teorias linguísticas. Linguas e Instrumentos linguísticos. n. 4/5, p. 7-32, Campinas, 1998.

PÊCHEUX, M. Língua, linguagens, discurso. In: PIOVEZANI, C.; SARGENTINI, V. (Org.) Legados de Michel Pêcheux: inéditos em Análise do discurso. São Paulo: Contexto, 2011, p. 63-75.

PIOVEZANI, C. Saussure e o discurso: O Curso de Linguística Geral lido pela Análise do discurso. Alfa (Revista de Linguística da UNESP), São Paulo, v. 52, n. 1, p. 7-20. 2008. 
PIOVEZANI, C. Verbo, Corpo e Voz: dispositivos de fala pública e produção da verdade no discurso político. São Paulo: Editora UNESP, 2009.

PUECH, C. L'émergence de la notion de "discours" en France et les destins du saussurisme. Langages. Paris, n. 159, p. 93-110, 2005.

PUECH, C. A emergência do paradigma semiótico-estrutural na França. In: SARGENTINI, V.; PIOVEZANI, C.; CURCINO, L. (Org.) Discurso, Semiologia e História. São Carlos: Claraluz, 2011, p. 19-63.

SAUSSURE, F. de. Curso de Lingüistica Geral. São Paulo, Cultrix, 2000. 


\section{Abstract \\ The value of Saussure for discourse studies}

What is Saussure's place in the constitution and developments of discourse studies? In order to reflect on what was said about him by some of his contemporaries and other thinkers in the first decades and the beginning of the second half of the twentieth century in Europe, we will not seek to answer this question without first exposing some of his contingencies and examining certain answers that could be given to it. In this regard, we will consider the different receptions of the Course in General Linguistics in France, from the initial moment of its publication to the end of the 1990s. We will then return to the reading that the Discourse Analysis did of Saussure's work in the late 1960s and in the early 1970s. With this in mind, we can make notes about the importance of the Course to Pêcheux and his group, either as a work that presents itself as a starting point or as a work to be refused.

Keywords: Saussure. Value. Discourse 